\title{
PERSPECTIVE Genomics of schizophrenia: time to consider the gut microbiome?
}

\author{
TG Dinan $^{1,2}$, YE Borre ${ }^{1}$ and JF Cryan ${ }^{1,3}$
}

\begin{abstract}
Research into the genomics of schizophrenia promises much, but so far is resplendent with failures to replicate, and has yielded little of therapeutic potential. Within our bodies resides a dynamic population of gut microbes forming a symbiotic superorganism comprising a myriad of bacteria of approximately $10^{14}$ cells, containing 100 times the number of genes of the human genome and weighing approximately the same as the human brain. Recent preclinical investigations indicate that these microbes majorly impact on cognitive function and fundamental behavior patterns, such as social interaction and stress management. We are pivotally dependent on the neuroactive substances produced by such bacteria. The biological diversity of this ecosystem is established in the initial months of life and is highly impacted upon by environmental factors. To date, this vast quantity of DNA has been largely ignored in schizophrenia research. Perhaps it is time to reconsider this omission.
\end{abstract}

Molecular Psychiatry (2014) 19, 1252-1257; doi:10.1038/mp.2014.93; published online 7 October 2014

The present classification of psychotic illness owes much to the work of Emil Kraepelin ${ }^{1}$ and he observed the fact that psychotic illness tended to run in certain families. Since then twin and adoption studies have provided further support for the view that schizophrenia is frequently a disorder with a genetic basis. It is generally accepted that the concordance rate in monozygotic twins is greater than that observed in dizygotic twins, ${ }^{2,3}$ and adopted children of schizophrenic parents have the same risk of schizophrenia as their biological rather than their adoptive parents. ${ }^{4,5}$ In recent years the availability of high-throughput, relatively inexpensive, sequencing technology has enabled a detailed exploration of the molecular genetics of schizophrenia in large patient populations. ${ }^{6,7}$ Risk loci have been identified from both genome-wide association ${ }^{8,9}$ and copy number variant studies. ${ }^{10,11}$ However, the field since its inception is resplendent with claims, counterclaims and major failures to replicate. ${ }^{12-14}$ Even more recent findings that have been replicated account for only a fraction of the heritability. In this article we explore the view that the genomic analysis of schizophrenia to date has been far too limited, and fails to capture the true genomic diversity of the human body.

Within our bodies resides a dynamic population of microbes forming a symbiotic super-organism with whom we have coevolved. ${ }^{15}$ Recent investigations indicate that these microbes majorly impact on cognitive function and fundamental behavior patterns, such as social interaction and stress management. The collective microbiome comprises a myriad of bacteria of approximately $10^{14}$ cells, containing 100 times the number of genes of the human genome. ${ }^{15,16}$ Despite evolution of this microbiome for 500 million years, ${ }^{17,18}$ only recent advances in sequencing technology have allowed us to appreciate the full complexity of the host-microbe interrelationship. The gut microbiota is a highly developed organ of immense metabolic complexity and has approximately the same weight as the human brain. It is now clear that the gut microbiota plays a key role in the life and health of the host by protecting against pathogens, metabolizing dietary nutrients and drugs, and influencing the absorption and distribution of dietary fat. ${ }^{17}$ However, the influence of the microbiota extends beyond the gastrointestinal tract, playing a major role in the development and functioning of the central nervous system (CNS). ${ }^{19-21}$ Among the many substances produced by the gut microbiota are key central neurotransmitters whose influence extends beyond the enteric nervous system to the brain. To date no effort has been made to analyse this complex genomic structure in schizophrenia or other complex psychiatric disorders.

The composition and function of the intestinal microbiota has been the subject of intense scrutiny, first using culture-dependent microbiological techniques ${ }^{22}$ and, more recently, using cultureindependent $16 \mathrm{~S}$ rRNA gene sequence-based techniques, which allow greater insight into the microbial composition and diversity of this 'virtual' complex. ${ }^{23,24}$ Whereas advances in metagenomic technologies have revealed the composition of the human gut microbiota from early infancy ${ }^{25}$ through to elderly, ${ }^{26}$ far less is known about the physiological impact this microbiota has on host health, including that of the brain. Indeed, understanding the influence of the gut microbiota on host health has been described as one of the most exciting areas in the field of medicine. ${ }^{27}$

At birth the human brain is highly underdeveloped and the gut is generally regarded as entirely sterile. However, it is worth noting that there is an increasing body of evidence challenging the sterile-womb paradigm ${ }^{28}$ and that transmission of certain microbes already occurs in utero. Nonetheless, passage through the birth canal exposes the baby to the mother's microbiota. The initial colonization is dictated by the mother's microbes and the hospital environment. This colonization plays a fundamental role in brain development in the early postnatal weeks. The subsequent microbial composition of the neonatal gut is influenced by a number of factors, including antibiotic use, diet and various environmental factors. ${ }^{29}$ For example, the microbiota of formulafed infants has been reported to be more diverse than that of

${ }^{1}$ Alimentary Pharmabiotic Centre, University College, Cork, Ireland; ${ }^{2}$ Department of Psychiatry, Cork University Hospital, University College Cork, Cork, Ireland and ${ }^{3}$ Department of Anatomy and Neuroscience, University College Cork, Cork, Ireland. Correspondence: Professor TG Dinan, Department of Psychiatry, Cork University Hospital, University College Cork, Wilton, Cork, Ireland.

E-mail: t.dinan@ucc.ie

Received 1 April 2014; revised 6 June 2014; accepted 8 July 2014; published online 7 October 2014 
breast-fed infants, containing higher proportions of Bacteroides, Clostridium and Enterobacteriaceae. Furthermore, vaginally delivered infants are colonized by the fecal and vaginal bacteria of the mother, most notably lactobacilli, whereas infants delivered by caesarean section are colonized by other bacteria from environmental sources including health-care workers, air, medical equipment and other newborns. ${ }^{30}$

\section{BRAIN-GUT COMMUNICATION}

The concept of the brain-gut axis has emerged from the pioneering observations of some of the greats of modern physiology and medicine, namely, Beaumont, Darwin, Pavlov and Cannon. ${ }^{19,31}$ More recently, given the growing realisation of the importance of the microbiota in modulating health, the brain-gut axis has been extended to the brain-gut-microbiota axis, ${ }^{32-34}$ which represents a complex network of communication between the gut, microbiota and the brain, which modulate immune, gastrointestinal and CNS functions. ${ }^{32,35}$ Several routes of communication between the brain and gut have been explored. ${ }^{36}$ The vagus nerve provides a bidirectional route for information flow and specific gut-based lactobacilli species have been shown to lose their ability to communicate with the brain if an animal has been vagotomised. ${ }^{37}$ There is also a growing appreciation that the hypothalamicpituitary-adrenal axis and cytokines from the immune system both have a role. ${ }^{38}$ Tryptophan absorption from the gut into the peripheral circulation regulates both the central serotonin and glutamate systems. ${ }^{39}$ Short-chain fatty acids such as butyrate and propionate are the product of microbial activity in the gut, and permeate into the bloodstream. Butyrate is an established histone deacetylase inhibitor. The short-chain fatty acids act in brain regions through two discrete seven-transmembrane G-proteincoupled receptors, ${ }^{40}$ free fatty acid receptors 2 and 3, and have been implicated in autistic behavior. ${ }^{41}$

\section{Microbes and neurotransmission}

Which of the 4-5 million nonredundant bacterial genes that have been sequenced from the human gut are fundamental for brain development? At this point we do not know. It is tempting to speculate that those microbes that produce and secrete neuromodulators or their precursors have an especially important role to play in neurodevelopment. Gamma-aminobutyric acid, which is the main inhibitory neurotransmitter in the human brain, is produced by many lactobacilli, and for most babies born per vaginum these are the first bacteria to which they are exposed. As mentioned above, other essential neurotransmitters such as serotonin (5-HT), norepinephrine and dopamine (DA) are also produced by microbes. For example, certain Lactobacillus and Bifidobacterium species produce gamma-aminobutyric acid; Escherichia, Bacillus and Saccharomyces spp. produce noradrenaline; Candida, Streptococcus, Escherichia and Enterococcus spp. produce 5 -HT; Bacillus produces DA; and Lactobacillus produces acetylcholine. $^{42,43}$ It is not clear if these bacterial genes, which are relevant to neuroscience, are exact copies of the human version and if the latter have evolved by horizontal gene transfer. Such neurotransmitters have a key role in microbe to microbe communication and have important endocrine functions within the host. ${ }^{44}$ We do not know if polymorphisms exist in microbial genes that are relevant to host physiology and may mirror similar polymorphisms in the host. Whereas microbes can induce important epigenetic alterations in humans, no epigenetic mechanisms have been reported in microbes.

There are a variety of techniques used for studying the impact of the gut microbiota on the brain; these techniques include germ-free (GF) studies in mice (where animals are raised in a bacteria-free environment), antibiotic and probiotic studies, infection studies and fecal transplantation. ${ }^{19,45}$ Matsumoto et al. ${ }^{46}$ assessed the cerebral metabolome of GF mice and found 196 metabolites of which 23 were at least 1.6-fold higher in GF than in ex-GF mice, whereas for 15 metabolites the reverse was true. Metabolites involved in glycolytic pathways were significantly higher in GF than in ex-GF mice. Concentrations of DA were twofold higher in GF than in ex-GF mice. In the cerebrum of ex-GF mice the concentration of tryptophan, the precursor of $5-\mathrm{HT}$, was enhanced but the study failed to find differences in 5-HT levels. Levels of gamma-aminobutyric acid were similar in the brains of GF and ex-GF mice but plasma concentrations differed. These data are consistent with the view that gama-aminobutyric acid produced by gut bacteria influences the brain via the vagus nerve and not by directly acting within the brain. As DA remains the key neurotransmitter associated with schizophrenia pathophysiology and treatment, ${ }^{47}$ it may be relevant that levels within the brain are partly regulated by gut microbes. A pioneering study by Heijtz et al. ${ }^{48}$ showed that mice developmentally lacking any microbiota have elevations in DA turnover in the striatum coupled with a hyperactivity phenotype. Moreover, Sudo's group showed that the gut microbiota has a critical role in the production of biologically active, free catecholamines including DA in the gut lumen of mice. ${ }^{49}$

$A$ recent study ${ }^{20}$ demonstrated that the consequences of growing up GF extends to a clear increase in the hippocampus in both 5-HT and 5-hydroxyindoleacetic acid, its main metabolite, over the normal levels of these neurochemicals. Despite the increased $5-\mathrm{HT}$ concentration observed, there was no altered expression of the Tph2 gene, the key CNS isoform of the enzyme responsible for the synthesis of 5-HT from tryptophan. No alteration in gene expression level was found for either the serotonin transporter gene or the range of serotonergic receptor genes evaluated $\left(5-\mathrm{HT}_{1 \mathrm{~A}}, 5-\mathrm{HT}_{6}\right.$ and $\left.5-\mathrm{HT}_{2} \mathrm{C}\right)$. The alterations observed are sex specific, occurring only in males, in contrast with the immunological and neuroendocrine effects, which are evident in both sexes. Concentrations of tryptophan, the precursor of serotonin, are increased in the plasma of male GF animals, suggesting a humoral route through which the microbiota can influence CNS serotonergic neurotransmission. Interestingly, colonization of the GF animals post weaning is insufficient to reverse the CNS neurochemical consequences in adulthood of an absent microbiota in early life despite the peripheral availability of tryptophan being restored to baseline values. In addition, reduced anxiety in GF animals is also normalized following restoration of the intestinal microbiota. An earlier study by Desbonnet et al. ${ }^{50}$ reported increase in tryptophan levels in rats treated with the probiotic Bifidobacerium infantis 35624 . This probiotic has been shown to have antidepressant action in preclinical models of depression and may thus constitute a psychobiotic that is a probiotic with a mental health benefit. ${ }^{51}$ Overall, accumulating evidence points to key functions of microbial genes in neuronal activity, supplying the developing as well as mature brain with numerous neuroactive compounds, which have an impact on health and disease and may lie at the heart of behavioral disturbances. For example, in rodents, as in man, phencyclidine induces significant behavioral changes that are ameliorated by antipsychotics and also by the microbial produced histone deacetylase inhibitor-butyrate. In contrast, a murine model of autism reveals a strong association between changes in the gut microbiota and increased levels of cecal butyrate..$^{52}$

\section{Microbiota and schizophrenia-like behavior}

The maternal immune-activation mouse model is known to display features of schizophrenia. ${ }^{53,54}$ Hsiao et al. ${ }^{55}$ showed that maternal immune-activation offspring display an altered serum metabolomic profile. They used oral treatment of such offspring with the human commensal Bacteroides fragilis. Treatment corrected gut permeability, altered microbial composition, and ameliorated defects in communicative, stereotypic, anxiety-like 


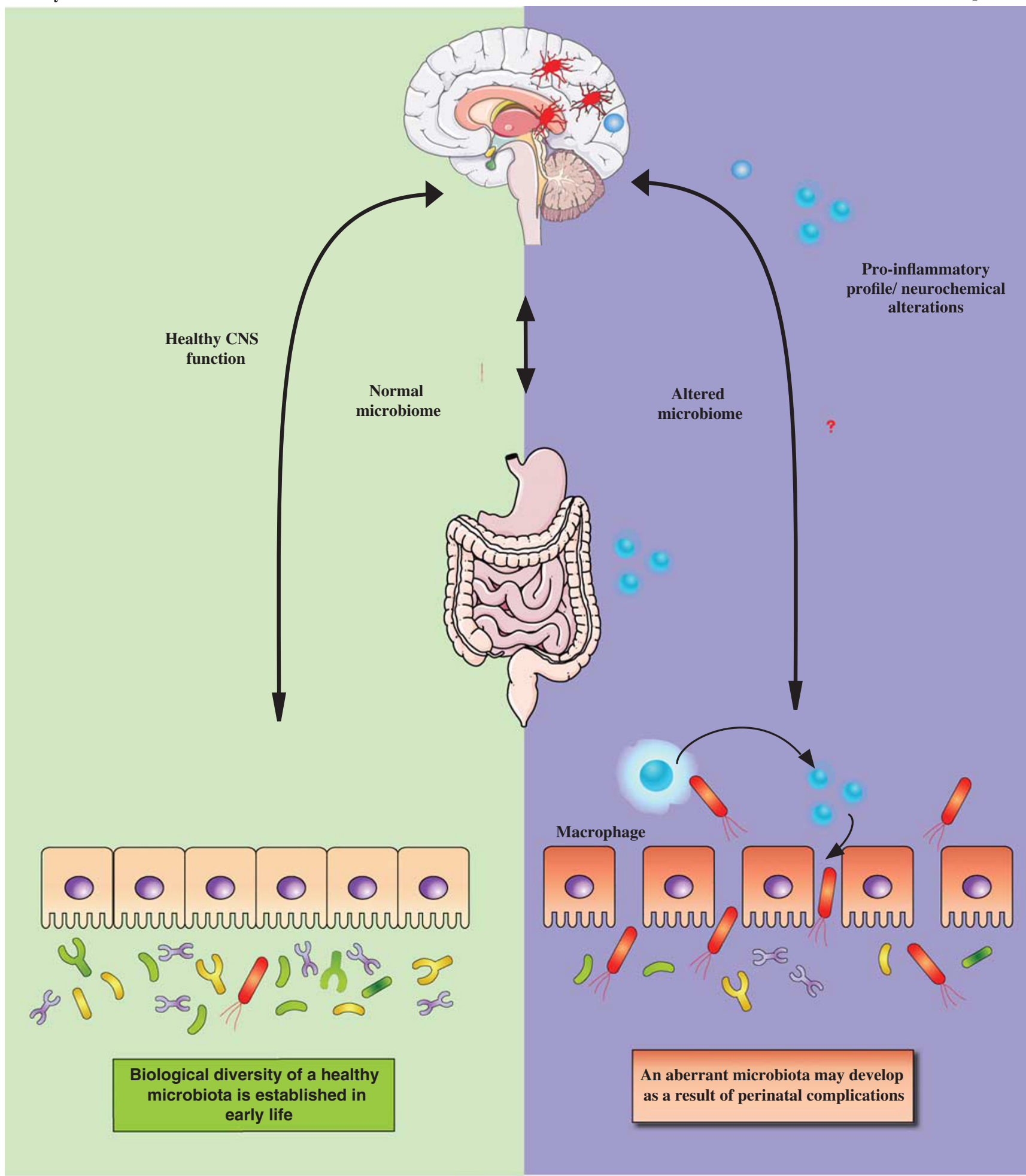

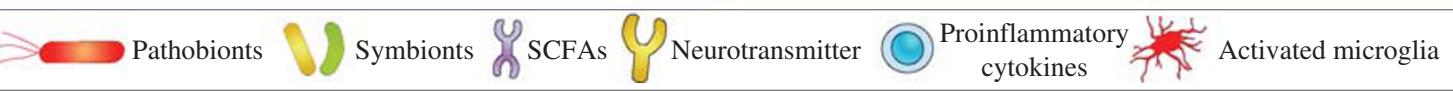

Figure 1. The bidirectional routes of communication between the brain and the gut microbiota. These include the vagus nerve, short-chain fatty acids, tryptophan, cortisol and cytokines. The figure also proposes a mechanism by which the gut microbiome could alter central neurochemistry in patients with schizophrenia. 
and sensorimotor behaviors. Treating naive mice with a metabolite that is increased by maternal immune activation and normalized by $B$. fragilis resulted in behavioral abnormalities, supporting the view that gut bacteria effects on the host metabolome impact behavior. We examined social behavior in GF mice using the three-chamber sociability test, ${ }^{56}$ one of the most widely used assays of social behavior. In the first study, a GF mouse was placed in the middle chamber with a second mouse in the first chamber and a third empty chamber. A conventionally colonized mouse tends to spend more time with a second mouse than without, while the GF mouse did not discriminate between chambers with or without a mouse. In a second experiment, a GF mouse or a conventionally colonized mouse is placed in the middle chamber with a familiar mouse in the first chamber and an unfamiliar mouse in the third chamber. The conventionally colonized mouse spends more time with the unfamiliar mouse while the GF mouse shows no preference for either the familiar or the unfamiliar mouse. The overall pattern of behavior in GF mice is highly schizoid or autistic, with a capacity for reversal if the animal is colonized at an early stage. The behavioral deficits seen in GF mice are far more pronounced in males than in females, a fact consistent with the epidemiological data on schizophrenia.

Postnatal gut microbial colonization occurs in parallel with cognitive development. There is increasing evidence to support the view that the evolving cognitive activity is critically dependent on the microbiota and its metabolic outputs. ${ }^{18,57}$ Gareau et al. ${ }^{58}$ used a novel object recognition test examining for dorsal hippocampal function and exploration of a T-maze to study GF mice. These animals displayed an absence of nonspatial and working memory accompanied by decreases in hippocampal brain-derived neurotrophic factor. The data indicate that compared with colonized animals GF mice display significant cognitive deficits. The authors conclude that the presence of microbes is crucial for the development of hippocampus-dependent memory.

The protozoa Toxoplasma gondii is known to cause major perturbation to the gut microbiota ${ }^{59}$ and is a recognized environmental risk factor for schizophrenia. ${ }^{60}$ In rodents it is capable of altering host behavior and underlying anxiety levels. ${ }^{61}$ Recent studies in healthy elderly indicate that latent infection can lead to deficits in goal-directed learning with alterations in dopaminergic neural transmission (Figure 1). ${ }^{62}$

\section{Schizophrenia, prematurity and microbiota}

It is well established that premature delivery increases the risk of developing schizophrenia. ${ }^{63,64}$ This may have major relevance in countries where cesarian section rates are now in excess of $50 \%$, most notably China and Brazil, and where a majority of these planned deliveries occur at least 2-3 weeks prior to full term. Those who develop schizophrenia and were born prematurely tend to show premorbid social withdrawal and an early age at illness onset. ${ }^{65}$

Ehninger et $a l^{66}$ studied the stability and function of early microbial colonizers of the premature infant gut. Overall, the premature infant gut has low individual but high interindividual microbial diversity. Over a 1-week period, the early gut microbial community transitions to a community with a higher representation of obligate anaerobes, emphasizing both taxonomic and metabolic instability during colonization. Penders et al. ${ }^{67}$ conclude that two of the most important determinants of the gut microbiotic composition in infants are the mode of delivery and gestational age. Infants born through cesarean section had lower numbers of Bifidobacteria and Bacteroides, whereas they were more often colonized with C. difficile, compared with vaginally born infants. There is now increasing evidence that Bifidobacteria have positive benefits for the developing brain ${ }^{68,69}$ while $C$. difficile is an aberrant undesirable pathogen. ${ }^{70}$ Cases of schizophrenia and autism have been associated with $C$. difficile infection and reported as mediated by a phenylalanine derivative produced by the bacteria. ${ }^{71}$ There are no prospective studies available on the outcome of otherwise healthy babies who have colonized this organism.

\section{Behavioral genetics and microbiota}

Is the view that genes in the microbiota are relevant to the etiology of schizophrenia consistent with the behavioral genetic data? It is a fact that the microbiota architecture within members of a family has greater similarity than with individuals outside the family. ${ }^{72}$ This fact is consistent with the clustering of schizophrenia within certain families. That monozygotic twins show greater microbial commonality than do dizygotic twins has been demonstrated $^{73,74}$ and is once again consistent with the schizophrenia twin studies. Both the monozygotic and dizygotic twins if born per vaginum will have initial identical exposure to the mother's microbiota. Subsequent differences in concordance rates are presumably due to the fact that monozygotic twins have an identical immune system, which is not the case for dizygotic twins. Having an identical immunology will allow for the establishment of a similar microbiota. There are no human adoption studies focusing on the microbiota. However, it is clear that the initial microbiota formed has a maternal signature ${ }^{75,76}$ derived from the biological mother and subsequent alteration will be determined by the diet in the adoptive home and perhaps antibiotic exposure.

Let us take as a tentative lesson, the case of peptic ulcer disease, which was previously viewed as a stress-related disorder. ${ }^{77}$ Clustering within families has been recognized ${ }^{78}$ and monozygotic twins have a higher concordance than dizygotic twins. ${ }^{79}$ Likewise, adoption studies in peptic ulcer disease yield a similar finding to that of schizophrenia. ${ }^{80}$ Thanks to the pioneering work of Marshall and Warren, which identified $H$. pylori as the main causative agent in peptic ulcer disease, the disease is now readily treatable. ${ }^{81,82} \mathrm{We}$ could conduct genome-wide association studies for decades and never find the cause of peptic ulcer disease. Only by studying the microbiota was a causal agent established. This analogy is obviously tempered by the obvious behavioral complexity of schizophrenia relative to a disorder with a distinct pathology.

\section{CONCLUSION}

The human genome is greater than the DNA content in our cells. It also includes the genetic material in the gut microbiota, our 'virtual' organ. We live in a symbiotic relationship with microbes, and increasing evidence points to the fact that without the activity of these microbes our social interactions and cognitive functioning would not have evolved to the extent it has. We are pivotally dependent on the neuroactive substances produced by such bacteria. The biological diversity of this ecosystem is established in the initial months of life, is highly impacted upon by environmental factors, and has a role throughout the lifespan. The accumulating preclinical data provide support for the view that an analysis of the gut microbiota in schizophrenia may yield valuable information.

\section{CONFLICT OF INTEREST}

The authors declare no conflict of interest.

\section{ACKNOWLEDGMENTS}

We are supported in part by Science Foundation Ireland in the form of a centre grant (Alimentary Pharmabiotic Centre Grant Number SFI/12/RC/2273); by the Health Research Board of Ireland (Grant Numbers HRA_POR/2011/23 and HRA_POR/ 2012/32); and received funding from the European Community's Seventh Framework Programme Grant MyNewGut under Grant Agreement No. FP7/2007-2013. The Centre has conducted studies in collaboration with several companies including GSK, Pfizer, Cremo, Suntory, Wyeth and Mead Johnson. 


\section{REFERENCES}

1 Kraepelin E. 100 years of psychiatry. Vertex 2010; 21: 317-320.

2 Fabi E, Fusco A, Valiante M, Celli R. Genetics and epigenetics of schizophrenia. Clin Ter 2013; 164: e319-e324.

3 Fowler T, Zammit S, Owen MJ, Rasmussen F. A population-based study of shared genetic variation between premorbid IQ and psychosis among male twin pairs and sibling pairs from Sweden. Arch Gen Psychiatry 2012; 69: 460-466.

4 Tienari P, Lahti I, Sorri A, Naarala M, Moring J, Wahlberg KE et al. The Finnish adoptive family study of schizophrenia. J Psychiatric Res 1987; 21: 437-445.

5 Shastry BS. Schizophrenia: a genetic perspective (review). Int J Mol Med 2002; 9 : 207-212.

6 Singh S, Kumar A, Agarwal S, Phadke SR, Jaiswal Y. Genetic insight of schizophrenia: past and future perspectives. Gene 2014; 535: 97-100.

7 Giusti-Rodriguez P, Sullivan PF. The genomics of schizophrenia: update and implications. J Clin Invest 2013; 123: 4557-4563.

8 Corvin A, Morris DW. Genome-wide Association Studies: Findings at the Major Histocompatibility Complex Locus in Psychosis. Biol Psychiatry 2014; 75: 276-283.

9 Nishizawa D, Fukuda K, Kasai S, Hasegawa J, Aoki Y, Nishi A et al. Genome-wide association study identifies a potent locus associated with human opioid sensitivity. Mol Psychiatry 2014; 19: 55-62.

10 Kirov G, Rees E, Walters JT, Escott-Price V, Georgieva L, Richards AL et al. The penetrance of copy number variations for schizophrenia and developmental delay. Biol Psychiatry 2014; 75: 378-385.

11 Mulle JG, Pulver AE, McGrath JA, Wolyniec PS, Dodd AF, Cutler DJ et al. Reciprocal duplication of the williams-beuren syndrome deletion on chromosome $7 q 11.23$ is associated with schizophrenia. Biol Psychiatry 2014; 75: 371-377.

12 Rizig MA, McQuillin A, Puri V, Choudhury K, Datta S, Thirumalai S et al. Failure to confirm genetic association between schizophrenia and markers on chromosome 1 q23.3 in the region of the gene encoding the regulator of G-protein signaling 4 protein (RGS4). Am J Med Genet B Neuropsychiatr Genet 2006; 141B: 296-300.

13 Fujii T, lijima Y, Kondo H, Shizuno T, Hori H, Nakabayashi T et al. Failure to confirm an association between the PLXNA2 gene and schizophrenia in a Japanese population. Prog Neuropsychopharmacol Biol Psychiatry 2007; 31: 873-877.

14 Amagane $\mathrm{H}$, Watanabe $\mathrm{Y}$, Kaneko N, Nunokawa A, Muratake T, Ishiguro $\mathrm{H}$ et al. Failure to find an association between myosin heavy chain 9, non-muscle (MYH9) and schizophrenia: a three-stage case-control association study. Schizophr Res 2010; 118: 106-112.

15 Eckburg PB, Bik EM, Bernstein CN, Purdom E, Dethlefsen L, Sargent M et al. Diversity of the human intestinal microbial flora. Science 2005; 308: 1635-1638.

16 Possemiers S, Bolca S, Verstraete W, Heyerick A. The intestinal microbiome: separate organ inside the body with the metabolic potential to influence the bioactivity of botanicals. Fitoterapia 2011; 82: 53-66.

17 Cho I, Blaser MJ. The human microbiome: at the interface of health and disease. Nat Rev Genet 2012; 13: 260-270.

18 Stilling RM, Dinan TG, Cryan JF. Microbial genes, brain \& behaviour - epigenetic regulation of the gut-brain axis. Genes Brain Behav 2014; 13: 69-86.

19 Cryan JF, Dinan TG. Mind-altering microorganisms: the impact of the gut microbiota on brain and behaviour. Nat Rev Neurosci 2012; 13: 701-712.

20 Clarke G, Grenham S, Scully P, Fitzgerald P, Moloney RD, Shanahan F et al. The microbiome-gut-brain axis during early life regulates the hippocampal serotonergic system in a sex-dependent manner. Mol Psychiatry 2013; 18: 666-673.

21 Forsythe $\mathrm{P}$, Kunze WA, Bienenstock J. On communication between gut microbes and the brain. Curr Opin Gastroenterol 2012; 28: 557-562.

22 Grenham S, Clarke G, Cryan JF, Dinan TG. Brain-gut-microbe communication in health and disease. Front Physiol 2011; 2: 94.

23 Armougom F, Raoult D. Use of pyrosequencing and DNA barcodes to monitor variations in Firmicutes and Bacteroidetes communities in the gut microbiota of obese humans. BMC Genomics 2008; 9: 576.

24 Qin J, Li R, Raes J, Arumugam M, Burgdorf KS, Manichanh C et al. A human gut microbial gene catalogue established by metagenomic sequencing. Nature 2010; 464: 59-65.

25 Palmer C, Bik EM, DiGiulio DB, Relman DA, Brown PO. Development of the human infant intestinal microbiota. PLoS Biol 2007; 5: e177.

26 Claesson MJ, Jeffery IB, Conde S, Power SE, O'Connor EM, Cusack S et al. Gut microbiota composition correlates with diet and health in the elderly. Nature 2012; 488: 178-184.

27 Shanahan F. The gut microbiota-a clinical perspective on lessons learned. Nat Rev Gastroenterol Hepatol 2012; 9: 609-614.

28 Funkhouser LJ, Bordenstein SR. Mom knows best: the universality of maternal microbial transmission. PLoS Biol 2013; 11: e1001631.

29 Dominguez-Bello MG, Costello EK, Contreras M, Magris M, Hidalgo G, Fierer N et al. Delivery mode shapes the acquisition and structure of the initial microbiota across multiple body habitats in newborns. Proc Natl Acad Sci USA 2010; 107: 11971-11975.
30 Faa G, Gerosa C, Fanni D, Nemolato S, van Eyken P, Fanos V. Factors influencing the development of a personal tailored microbiota in the neonate, with particular emphasis on antibiotic therapy. J Matern Fetal Neonatal Med 2013; 26 35-43.

31 Aziz Q, Dore J, Emmanuel A, Guarner F, Quigley EM. Gut microbiota and gastrointestinal health: current concepts and future directions. Neurogastroenterol Motil 2013; 25: 4-15.

32 Rhee SH, Pothoulakis C, Mayer EA. Principles and clinical implications of the braingut-enteric microbiota axis. Nat Rev Gastroenterol Hepatol 2009; 6: 306-314.

33 Collins SM, Surette M, Bercik P. The interplay between the intestinal microbiota and the brain. Nat Rev Microbiol 2012; 10: 735-742.

34 O'Mahony SM, Hyland NP, Dinan TG, Cryan JF. Maternal separation as a model of brain-gut axis dysfunction. Psychopharmacology 2011; 214: 71-88.

35 Mayer EA. Gut feelings: the emerging biology of gut-brain communication. Nat Rev Neurosci 2011; 12: 453-466.

36 Dinan TG, Cryan JF. Melancholic microbes: a link between gut microbiota and depression? Neurogastroenterol Motil 2013; 25: 713-719.

37 Bravo JA, Forsythe P, Chew MV, Escaravage E, Savignac HM, Dinan TG et al. Ingestion of Lactobacillus strain regulates emotional behavior and central GABA receptor expression in a mouse via the vagus nerve. Proc Natl Acad Sci USA 2011; 108: $16050-16055$.

38 Jones MP, Dilley JB, Drossman D, Crowell MD. Brain-gut connections in functional GI disorders: anatomic and physiologic relationships. Neurogastroenterol Motil 2006; 18: 91-103.

39 Barry S, Clarke G, Scully P, Dinan TG. Kynurenine pathway in psychosis: evidence of increased tryptophan degradation. J Psychopharmacol 2009; 23: 287-294.

40 Tan J, McKenzie C, Potamitis M, Thorburn AN, Mackay CR, Macia L. The role of short-chain Fatty acids in health and disease. Adv Immunol 2014; 121: 91-119.

41 Adams JB, Johansen LJ, Powell LD, Quig D, Rubin RA. Gastrointestinal flora and gastrointestinal status in children with autism--comparisons to typical children and correlation with autism severity. BMC Gastroenterol 2011; 11: 22.

42 Lyte M. Probiotics function mechanistically as delivery vehicles for neuroactive compounds: Microbial endocrinology in the design and use of probiotics. Bioes says 2011 ; 33: $574-581$.

43 Lyte M. Microbial endocrinology in the microbiome-gut-brain axis: how bacterial production and utilization of neurochemicals influence behavior. PLOS Pathog 2013; 9: e1003726.

44 Lyte M. Microbial endocrinology: host-microbiota neuroendocrine interactions influencing brain and behavior. Gut Microbes 2014; 5: 3.

45 Foster JA, McVey Neufeld KA. Gut-brain axis: how the microbiome influences anxiety and depression. Trends Neurosci 2013; 36: 305-312.

46 Matsumoto M, Kibe R, Ooga T, Aiba Y, Sawaki E, Koga $Y$ et al. Cerebral lowmolecular metabolites influenced by intestinal microbiota: a pilot study. Front Syst Neurosci 2013; 7: 9.

47 Kopp S, Kelly KB, Gillberg C. Girls with social and/or attention deficits: a descriptive study of 100 clinic attenders. J Atten Disord 2010; 14: 167-181.

48 Diaz Heijtz R, Wang S, Anuar F, Qian Y, Bjorkholm B, Samuelsson A et al. Normal gut microbiota modulates brain development and behavior. Proc Natl Acad Sci USA 2011; 108: 3047-3052.

49 Asano Y, Hiramoto T, Nishino R, Aiba Y, Kimura T, Yoshihara K et al. Critical role of gut microbiota in the production of biologically active, free catecholamines in the gut lumen of mice. Am J Physiol Gastrointest Liver Physiol 2012; 303: G1288-G1295.

50 Desbonnet L, Garrett L, Clarke G, Bienenstock J, Dinan TG. The probiotic Bifidobacteria infantis: an assessment of potential antidepressant properties in the rat. J Psychiatr Res 2008; 43: 164-174.

51 Dinan TG, Stanton C, Cryan JF. Psychobiotics: a novel class of psychotropic. Biol Psychiatry 2013; 74: 720-726.

52 de Theije CG, Wopereis H, Ramadan M, van Eijndthoven T, Lambert J, Knol J et al. Altered gut microbiota and activity in a murine model of autism spectrum disorders. Brain Behav Immun 2014; 37: 197-206.

53 Ibi D, Nagai T, Nabeshima T, Yamada K. [Polyl:C-induced neurodevelopmental animal model for schizophrenia]. Nihon Shinkei Seishin Yakurigaku Zasshi 2011; 31: 201-207.

54 Bauman MD, losif AM, Smith SE, Bregere C, Amaral DG, Patterson PH. Activation of the maternal immune system during pregnancy alters behavioral development of rhesus monkey offspring. Biol Psychiatry 2014; 75: 332-341.

55 Hsiao EY, McBride SW, Hsien S, Sharon G, Hyde ER, McCue T et al. Microbiota modulate behavioral and physiological abnormalities associated with neurodevelopmental disorders. Cell 2013; 155: 1451-1463.

56 Desbonnet L, Clarke G, Shanahan F, Dinan TG, Cryan JF. Microbiota is essential for social development in the mouse. Mol Psychiatry 2014; 19: 146-148.

57 Bercik P. The microbiota-gut-brain axis: learning from intestinal bacteria? Gut 2011; 60: 288-289. 
58 Gareau MG, Wine E, Rodrigues DM, Cho JH, Whary MT, Philpott DJ et al. Bacterial infection causes stress-induced memory dysfunction in mice. Gut 2011; 60: 307-317.

59 Molloy MJ, Grainger JR, Bouladoux N, Hand TW, Koo LY, Naik S et al. Intraluminal containment of commensal outgrowth in the gut during infection-induced dysbiosis. Cell Host Microbe 2013; 14: 318-328.

60 Bhadra R, Cobb DA, Weiss LM, Khan IA. Psychiatric disorders in toxoplasma seropositive patients--the CD8 connection. Schizophr Bull 2013; 39: 485-489.

61 Vyas A, Kim SK, Giacomini N, Boothroyd JC, Sapolsky RM. Behavioral changes induced by Toxoplasma infection of rodents are highly specific to aversion of cat odors. Proc Natl Acad Sci USA 2007; 104: 6442-6447.

62 Beste C, Getzmann S, Gajewski PD, Golka K, Falkenstein M. Latent Toxoplasma gondii infection leads to deficits in goal-directed behavior in healthy elderly. Neurobiol Aging 2014; 35: 1037-1044.

63 Schieve LA, Boulet SL, Kogan MD, Yeargin-Allsopp M, Boyle CA, Visser SN et al Parenting aggravation and autism spectrum disorders: 2007 National Survey of Children's Health. Disabil Health J 2011; 4: 143-152.

64 Thomas P, Zahorodny W, Peng B, Kim S, Jani N, Halperin W et al. The association of autism diagnosis with socioeconomic status. Autism 2012; 16: 201-213.

65 Robinson EB, Munir K, Munafo MR, Hughes M, McCormick MC, Koenen KC Stability of autistic traits in the general population: further evidence for a continuum of impairment. J Am Acad Child Adolesc Psychiatry 2011; 50: 376-384.

66 Ehninger D, Sano Y, de Vries PJ, Dies K, Franz D, Geschwind DH et al. Gestational immune activation and Tsc2 haploinsufficiency cooperate to disrupt fetal survival and may perturb social behavior in adult mice. Mol Psychiatry 2012; 17: 62-70.

67 Penders J, Thijs C, Vink C, Stelma FF, Snijders B, Kummeling I et al. Factors influencing the composition of the intestinal microbiota in early infancy. Pediatrics 2006; 118: 511-521.

68 Savignac HM, Corona G, Mills H, Chen L, Spencer JP, Tzortzis G et al. Prebiotic feeding elevates central brain derived neurotrophic factor, N-methyl-D-aspartate receptor subunits and D-serine. Neurochem Int 2013; 63: 756-764.

69 Wall R, Ross RP, Shanahan F, O'Mahony L, Kiely B, Quigley E et al. Impact of administered bifidobacterium on murine host fatty acid composition. Lipids 2010; 45: 429-436.

70 Ferraris L, Butel MJ, Campeotto F, Vodovar M, Roze JC, Aires J. Clostridia in premature neonates' gut: incidence, antibiotic susceptibility, and perinatal determinants influencing colonization. PLoS ONE 2012; 7: e30594.

71 Shaw W. Increased urinary excretion of a 3-(3-hydroxyphenyl)-3-hydroxypropionic acid (HPHPA), an abnormal phenylalanine metabolite of Clostridia spp. in the gastrointestinal tract, in urine samples from patients with autism and schizophrenia. Nutr Neurosci 2010; 13: 135-143.

72 Spor A, Koren O, Ley R. Unravelling the effects of the environment and host genotype on the gut microbiome. Nat Rev Microbiol 2011; 9: 279-290.

73 Tims S, Derom C, Jonkers DM, Vlietinck R, Saris WH, Kleerebezem M et al. Microbiota conservation and BMI signatures in adult monozygotic twins. ISME $J$ 2013; 7: 707-717.

74 Hansen EE, Lozupone CA, Rey FE, Wu M, Guruge JL, Narra A et al. Pan-genome of the dominant human gut-associated archaeon, Methanobrevibacter smithii, studied in twins. Proc Natl Acad Sci USA 2011; 108: 4599-4606.

75 Azad MB, Konya T, Maughan H, Guttman DS, Field CJ, Chari RS et al. Gut microbiota of healthy Canadian infants: profiles by mode of delivery and infant diet at 4 months. CMAJ 2013; 185: 385-394.

76 Adlerberth I. Factors influencing the establishment of the intestinal microbiota in infancy. Nestle Nutr Workshop Ser Pediatr Program 2008; 62: 13-29, discussion 33.

77 Kasanen A, Forsstrom J. Social stress and living habits in the etiology of peptic ulcer. Ann Med Intern Fenn 1966; 55: 13-22.

78 Allely CS. Pain sensitivity and observer perception of pain in individuals with autistic spectrum disorder. Scientific World J 2013; 2013: 916178.

79 Bay B, Mortensen EL, Hvidtjorn D, Kesmodel US. Fertility treatment and risk of childhood and adolescent mental disorders: register based cohort study. BMJ 2013; 347: f3978.

80 Kawicka A, Regulska-llow B. How nutritional status, diet and dietary supplements can affect autism. A review. Rocz Panstw Zakl Hig 2013; 64: 1-12.

81 Veenstra-VanderWeele J, Blakely RD. Networking in autism: leveraging genetic, biomarker and model system findings in the search for new treatments. Neuropsychopharmacology 2012; 37: 196-212.

82 Bennett T, Boyle M, Georgiades K, Georgiades S, Thompson A, Duku E et al. Influence of reporting effects on the association between maternal depression and child autism spectrum disorder behaviors. J Child Psychol Psychiatry 2012; 53: 89-96.

(c) $(\$)$ This work is licensed under a Creative Commons AttributionBY NC ND NonCommercial-NoDerivs 3.0 Unported License. The images or other third party material in this article are included in the article's Creative Commons license, unless indicated otherwise in the credit line; if the material is not included under the Creative Commons license, users will need to obtain permission from the license holder to reproduce the material. To view a copy of this license, visit http://creativecommons.org/licenses/by-nc-nd/3.0/ 